\title{
Long-Term Results of Intraoral Excision for Submandibular Mixed Tumors
}

\author{
Yong Tae Hong, June Sun Kim, Cha Dong Yeo, and Ki Hwan Hong \\ Department of Otolaryngology-Head and Neck Surgery, Research Institute for Clinical Medicine of Chonbuk National University- \\ Biomedical Research Institute of Chonbuk National University Hospital, Jeonju, Korea
}

\section{경구강 절제술을 이용한 악하선 다형성 선종 치료의 장기 추적 결과}

홍용태 · 김준선 · 여차동 · 홍기환

전북대학교 의과대학 이비인후과학교실

Received June 29, 2018

Revised September 3, 2018

Accepted October 2, 2018

Address for correspondence

Ki Hwan Hong, MD, PhD

Department of Otolaryngology-

Head and Neck Surgery,

Research Institute for Clinical

Medicine of Chonbuk National

University-Biomedical Research

Institute of Chonbuk National

University Hospital,

567 Baekje-daero, Deokjin-gu,

Jeonju 54896, Korea

Tel $+82-63-250-1990$

Fax +82-63-250-1986

E-mail khhong@chonbuk.ac.kr
Background and Objectives Generally, the benign mixed tumors of the submandibular gland are successfully removed via transcervical approach. Recently, however, an alternative to the standard transcervical approach, such as an intraoral approach, has been reported. The surgical results of intraoral excisions for submandibular mixed tumors are discussed here.

Subjects and Method A retrospective review was carried out for 24 patients with submandibular mixed tumors who were past 3 years of follow-up. Surgical morbidities and benefits were studied using these data.

Results All patients successfully received an excision of the submandibular gland with tumor via an intraoral approach. Early postoperative complications of temporary lingual sensory paresis were developed in $75 \%$ of patients, followed by $54 \%$ of patients with temporary limitation of tongue movement. In contrast, there were no permanent paresis. Late complications were developed in two cases of mild deviation of tongue due to scar contracture on the floor of mouth, whereas two cases of tumor recurrence and one case of post-gustatory sweating syndrome were observed after surgery.

Conclusion This approach might be safe, if used with proper expertise, for the treatment of submandibular mixed tumors. The main advantages of this approach are that no external scars nor permanent injury are incurred to the related nerves. However, disadvantages are temporary lingual paresis and temporary limitation of tongue movement. Unfortunately, there were two cases showing recurrence after surgery and thus required more follow-up. Korean J Otorhinolaryngol-Head Neck Surg 2019;62(2):114-9

Key Words Intraoral excision · Mixed tumor · Submandibular gland.

\section{Introduction}

Benign tumors of the submandibular gland (SMG) are common tumors of the head and neck region, and the pleomorphic adenoma is the most common tumor. Patients usually present with a painless and mobile mass without any other

This is an Open Access article distributed under the terms of the Creative Commons Attribution Non-Commercial License (https://creativecommons.org/licenses/by-nc/4.0) which permits unrestricted non-commercial use, distribution, and reproduction in any medium, provided the original work is properly cited. associated symptoms. ${ }^{1)}$ The pleomorphic adenoma represents $60 \%$ to $70 \%$ of all neoplasm of the major salivary gland and comprises approximately $65 \%$ of tumors of the parotid and $57 \%$ of tumors of the $\mathrm{SMG}^{2}{ }^{2}$ This tumor should be treated primarily by total removal of the tumor and the involved salivary gland, and shows a very low recurrence rate after surgery. However, when the tumor is incompletely removed, the chance of having recurrence stands about $10 \%{ }^{3}{ }^{3}$ Generally, the benign mixed tumors of the SMG are 
removed through transcervically without any difficulty. However, this approach has a few complications, such as a neck scar and neurological injuries to the marginal mandibular, lingual and hypoglossal nerves. An alternative approach to the SMG is through an intraoral approach reported by Hong and $\mathrm{Kim}^{4)}$ recently. They suggested that the benign mixed tumor seems to be not severely adhered to the surrounding tissue, and all cases of benign tumors could dissected easily and removed with the SMG. However, in the chronically inflamed disorders of the SMG, the intraoral dissection of the gland is difficult due to the severe adhesion to the surrounding tissue and may need to change to the transcervical approach. Hong and Yang ${ }^{5)}$ reported 77 cases of intraoral excision of the benign submandibular disorders, such as chronic sialoadenitis, deep stones and mixed tumors. They reported that the major advantages of this approach are the avoidance of an external scar and of injury to the mandibular branch of the facial nerve or to the hypoglossal nerve. Most patients treated with intraoral approach complained of neurological problems of lingual nerve, but temporarily and resolved within at least 2 months after surgery. Kauffman, et al. ${ }^{6}$ also reported 9 cases of intraoral excision for the benign submandibular disorders. They suggested that the transoral approach has been used effectively and without complication in re- moving benign submandibular glands. Hong and Yang ${ }^{5)}$ reported 12 cases of the pleomorphic adenoma of the SMG. They removed the SMG successfully and suggested that this approach might be extended to the excision of the benign submandibular tumors. Especially, this approach is beneficial to young women because of the avoidance of an external scar and of nerve injury. In this study we treated 24 cases of submandibular mixed tumors via an intraoral approach. The surgical technique and postoperative morbidity are discussed.

\section{Subjects and Method}

For 24 patients of SMG mixed tumors, postoperative complications and long-term morbidity were reviewed over the past 20 years. All tumors were surgically removed via an intraoral approach after proper evaluation, such as fine needle aspiration cytology and computerized tomography (Fig. 1A) We obtained proper consent from the patients in keeping with the mandate of the Declaration of Helsinki. The study's aim, methods and all potential risks and benefits to each patient were explained as part of the consent process. Each subject was informed of their right to abstain from participation in the study. No potential subjects were found to be legally incompetent. We reviewed an Institutional Review Board ap-
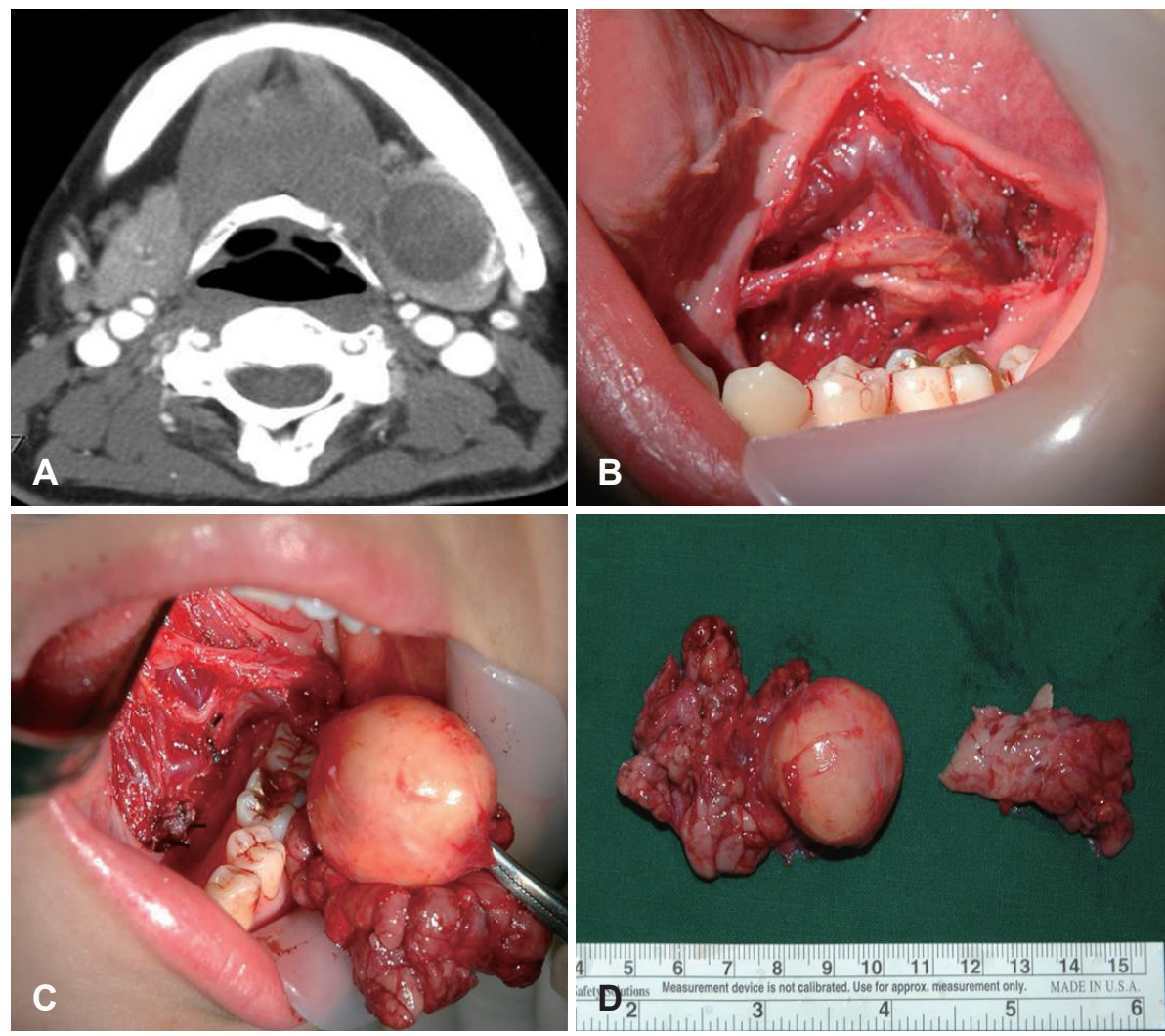

Fig. 1. CT image and operative view of intraoral excision for submandibular mixed tumor. CT image of the neck shows a homogenous hypodense mass in the submandibular gland (A). The hypoglossal and lingual nerves after removal of sublingual gland (B). Exposed submandibular gland and tumor (C). An excised submandibular gland with tumor (D). 
proval from Chonbuk National University Hospital and obtained proper consent from the patients. In the surgical technique described by Hong and $\mathrm{Kim}^{4}$ the surgical instruments required are as follows: tonsil dissector, tonsil hemostatic forceps, mouth props, metal tongue retractor and fiberoptic retractor or head light. Transnasal intubation was required for general anesthesia. After incision through the mucosa of lateral floor of the mouth from the orifice of Wharton's duct to the lingual side of the retromolar region. The sublingual gland was dissected and removed totally, with isolation of the Wharton's duct and preservation of the lingual nerve (Fig. 1B). The ligation of the duct was made at the orifice and the duct was isolated along the lingual nerve to the hilum of SMG. The lingual nerve can be seen through the distal part of the incision passing forwards and medially across the SMG duct. With retraction of the tongue and floor of the mouth, including the lingual nerve, the mylohyoid muscle was identified. Upon lateral and anterior retraction of the mylohyoid muscle, the submandibular gland is seen and the anterior and the upper surface of the gland is exposed by blunt dissection (Fig. 1C). The gland was gripped with long tissue forceps or tonsil hemostatic forceps, and dissected using a tonsil dissector or dissecting scissors and pulled up through the incision. The tumor capsule should not be grasped. If the tumor capsule is ruptured during the dissection, it could result in tumor contamination or seeding. The loop of the facial artery or arterial branch of the gland is demonstrated by blunt dissection and can frequently be freed completely from the gland, and these arteries should always be identified and ligated. The lingual and hypoglossal nerves were identified in the bed of the surgical field (Fig. 1D). The incised mucosa was sutured back loosely. A drain was inserted through the incision site and removed on the first or second postoperative day.

\section{Results}

All patients received an excision of the SMG with the tumor, via the intraoral approach. There were no conversion to transcervical approach during the removal of the tumors intraorally. 16 patients $(67 \%)$ were female and 8 were males $(33 \%)$; the male to female ratio was $1: 1.5$. The age of the patients ranged between 15 and 47 years, with a mean age of 31.5 years. The final diagnosis of tumors were based on the pathological findings by the pathologist. As in Table 1, postoperative complications were observed in most of the patients as follows: a temporary lingual nerve injury, such as paresthesia of the
Table 1. Long-term results after surgery

\begin{tabular}{lcl}
\multicolumn{1}{c}{ Complications } & $\begin{array}{c}\text { Temporary } \\
(\mathrm{n}, \%)\end{array}$ & $\begin{array}{c}\text { Permanent } \\
(\mathrm{n}, \%)\end{array}$ \\
\hline $\begin{array}{l}\text { Neurologic complications } \\
\text { Mandibular nerve }\end{array}$ & 0 & 0 \\
Lingual nerve & $18(75)$ & 0 \\
Hypoglossal nerve & 0 & 0 \\
Others & $13(54)$ & $2(8)$ \\
Limited tongue motion & 0 & $3(12)$ \\
Tumor recurrence & 0 & $1(4)$ \\
Frey's syndrome & & \\
\hline
\end{tabular}

tongue in 18 cases (75\%), resolved within 3-4 weeks in all cases; a mild limited movement of the tongue in the 13 cases (54\%), resolved within 4-6 weeks except 2 cases, which were left in tolerable states. There were no wound bleeding and abscess formation after surgery. The injuries of the hypoglossal or marginal mandibular nerves were not noted at all. Patients were satisfied of the circumvention of an external scar.

All patients were followed up for the recurrence of the tumor at least more than 3 years to 20 years (mean period: 8.7 years). There were 2 cases of tumor recurrences after surgery. A 23-year-old female patient showed a mass on the floor of the mouth. On past history, she had received SMG tumor removal intraorally 9 years ago at our clinic. But tumor had recurred on the floor of mouth at 16 months after 1st surgery. By reviewing operation record of this patient, the recurred tumor was removed easily with simple excision. However, she complained of mass on the floor of mouth again and we suspected tumor recurrence. CT image showed well circumscribed hypodense mass on the floor of mouth (Fig. 2A). The floor of mouth showed protruded and smooth surfaced mass (Fig. 2B). The mass was successfully removed intraorally and not recurred until now (Fig. 2C). Pathologically, a mass was confirmed as pleomorphic adenoma. A 45-year-old female patient showed a mass just beneath the neck skin on the SMG area 2 years after the removal of SMG tumor intraorally (Fig. 3B). We diagnosed as recurrence of tumor on the bed of SMG by reviewing CT images (Fig. 3A). The mass was successfully removed transcervically and not recurred following 9 years (Fig. 3C). Pathologically, a mass was also confirmed as pleomorphic adenoma. By reviewing the operation records, 2 patients which had recurrence had tumor rupture during the surgery due to large tumor size and relatively narrow surgical field. One patient developed Frey's syndrome 15 months after the operation. A 36-year-old man complained of post-gustatory sweating and flushing over an area of left submandib- 

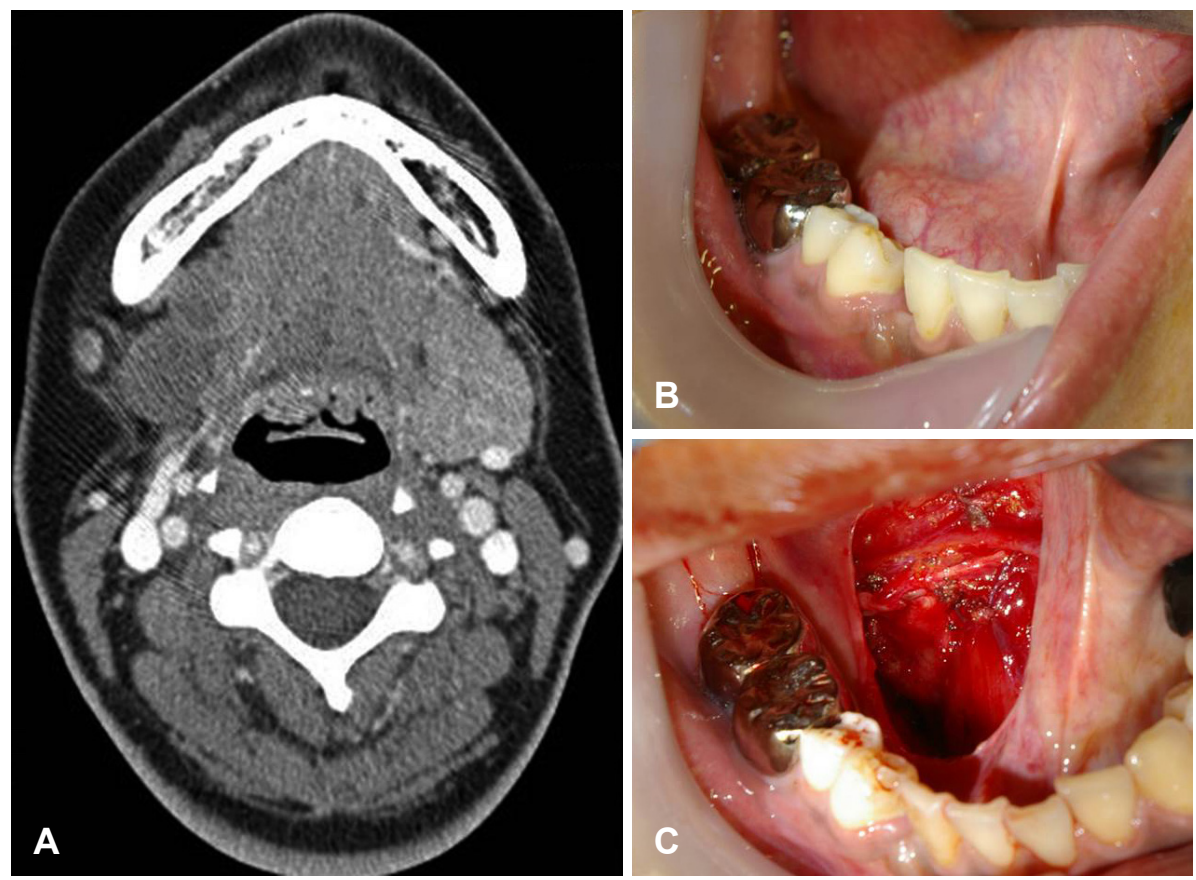

Fig. 2. CT image and operative view of patient with recurrence. CT image of the neck shows two homogenous hypodense mass on the right floor of mouth (A). Swelling of floor of mouth with well surfaced mass (B). After removal of sublingual mass intraorally $(C)$.
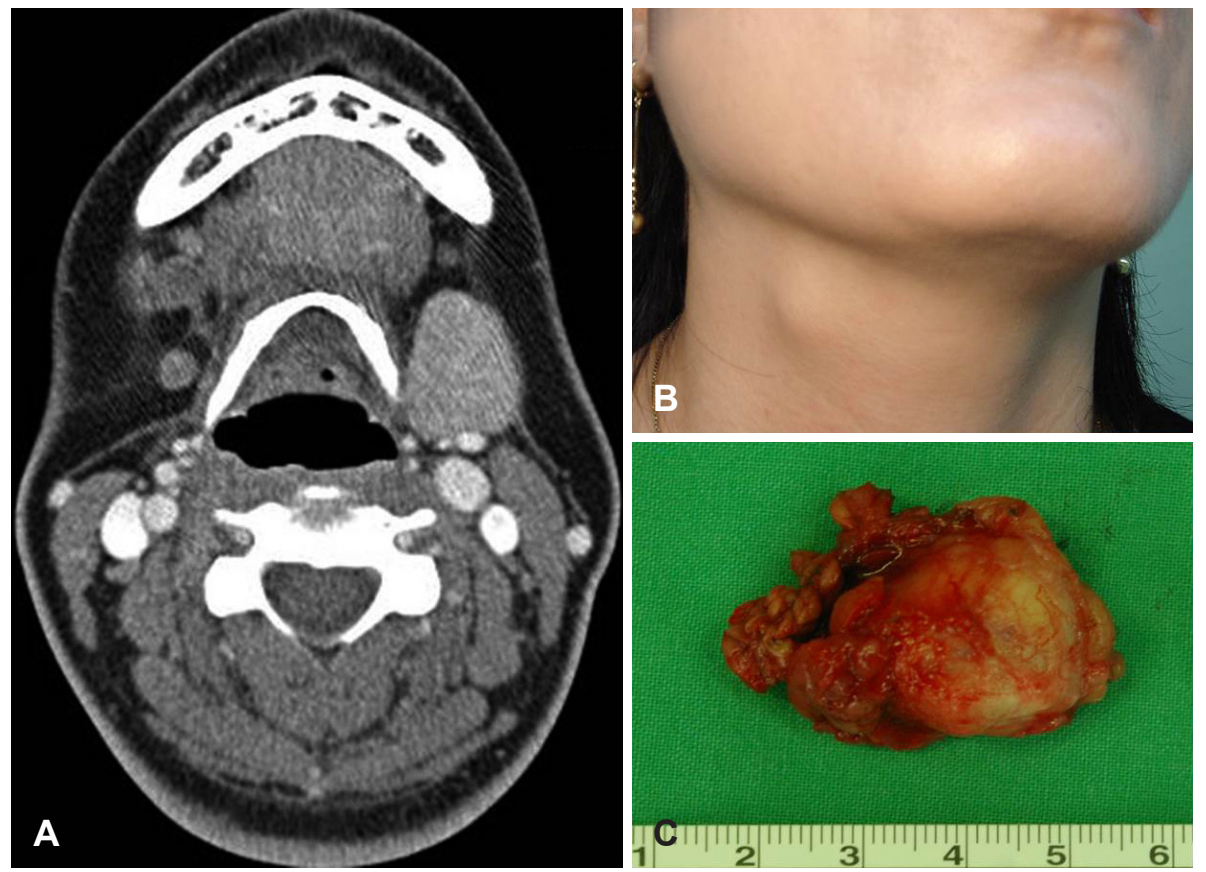

Fig. 3. CT image and operative view of patient with recurrence. CT image of the neck shows a homogenous hypodense mass on the right floor of mouth (A). A neck mass on the right lateral neck (B). Excised surgical specimens, tumor and remnant salivary tissue $(C)$.

ular skin after meal. We confirmed as Frey's syndrome by Minor's starch-iodine test. Fortunately, submandibular gustatory sweating was not severe, so active treatment was not required.

\section{Discussion}

The benign mixed tumors of the submandibular gland are usually identified as painless masses and presents for many years. They show little or no evidence of rapid growth, but over a long time period they might become quite large in size. ${ }^{2)}$ Generally, there is a consensus that fine needle aspiration cytology is of value in determining the management of SMG neoplasms. ${ }^{3)}$ Although the exact histological diagnosis is not always obtained, discrimination between benign and malignant processes is achieved with an accuracy of approximately $90 \%$. $^{7)}$ Mostly the diagnosis could be made by postoperative pathological study. On the surgical approach for 
the removal of the SMG mixed tumor, the transcervical approach is widely accepted and relatively simple. However, the transcervical procedure has frequently been associated with neurological complications, including the marginal mandibular nerve, lingual and hypoglossal nerves. ${ }^{7,8)}$ Recently, to improve cosmetic results, minimally invasive endoscopic and endo-robotic methods of submandibular gland resection through various routes have been assessed in experimental and clinical studies. ${ }^{9-12)}$ An operation time of endoscopic surgery, however, is significantly longer than that of other procedures. Alternative surgical approaches have been developed to avoid potential neurological risks and visible scarring in the upper neck. ${ }^{9-12)}$ Hong and $\mathrm{Kim}^{4)}$ reported a new surgical approach for intraoral removal of benign submandibular disorders and suggested that the intraoral approach could be extended as an alternative to the transcervical approach. In terms of neurological complications, an injury of the mandibular branch of the facial nerve is the most common complication associated with the transcervical approach. Erbek, et al. ${ }^{13)}$ reported an $17.8 \%$ incidence of damage to the marginal mandibular nerve, $2.2 \%$ of which was permanent. It usually consists of a temporary paralysis due to a compression and/or stretching injury, which can resolve spontaneously within a period of 3 months. However, in the intraoral approach the marginal mandibular nerve is not exposed during dissection and there is no possibility of facial nerve injury. This is also a major distinct advantage of the intraoral approach. In the transcervical approach, the lingual nerve should always be identified. Lesions associated with this nerve are not common and if they do occur are temporary. A 4.4\% incidence of permanent neurological deficit was described by Springborg and Møller. ${ }^{14)}$ while Turco, et al. ${ }^{8)}$ reported alterations of lingual sensitivity in $6 \%$ of cases. They reported that $12 \%$ of the patients in their study presented neurological sequelae, but only $4.8 \%$ of these were permanent. This incidence would have been higher if systematic examination had been carried out. However, in the intraoral approach, the lingual nerve is always compressed and/or stretched during traction of the floor of mouth, and the neurological problem of lingual nerve injury was observed in most patients temporarily. Most patients showed temporary injury lasting 2 to 3 weeks along the side of the tongue. Two patients complained of a mild reduction in sensation of the tongue lasting 3 months after surgery, but resolved by long term follow-up. The hypoglossal nerve is a critical structure which should be identified at all times in the transcervical and intraoral approach- es. The incidence of this nerve injury is rare, about $2.2 \%$, in the transcervical approach, ${ }^{13)}$ but not observed at all in the intraoral approach.

We have done careful follow up for patients who received intraoral approach since it's a new approach and the recurrence rate is not reported yet. At first year, we follow up the patients at postoperative 2 month, 6 month and then once a year. Unfortunately, there were 2 cases of tumor recurrence after surgery in this report. To prevent a recurrence of tumor during surgery, it's necessary to remove the tumor and SMG involved widely with a margin of normal tissue. A mixed tumor may have a pseudocapsule with pseudopods projecting away from it. ${ }^{2)}$ As we reviewed the pathologic results, the recurrences might be caused by tumor contamination due to a narrow surgical field in patients which had large tumors. As such, the proper exposure of surgical field is necessary and the tumor capsule should not be grasped during dissection. However, we think these problems may be reduced if surgeon's experience of this approach increases. Regarding aesthetic concerns, the transcervical approach may induce a scar problem, especially in young women or keloid characters. In the intraoral approach the avoidance of external scarring is a major advantage, especially in young patients or keloid characters.

The auriculo-temporal or Frey's syndrome is recurrent episodes of facial sweating and flushing which are localized to the distribution of the auriculo-temporal nerve in response to food ingestion. ${ }^{15,16)}$ The theory is an aberrant regeneration of the sectioned parasympathetic fibers of parotid gland to the vessels and sweat glands of the overlying skin. This gustatory sweating is most commonly reported following injury or surgery of parotid gland. Gustatory sweating also reported to occur following SMG removal or external auditory canal surgery. ${ }^{17)}$ A diagnosis of the Frey's syndrome following SMG removal was confirmed by Minor's starch-iodine test.

We have removed sublingual gland in all cases in order to improve surgical view. Recently, our skills in intraoral approach has improved so we are not removing the sublingual gland. However, patient reviewed in this study has all been treated at least 3 years from now. In the future, we are planning to compare the morbidity of patients which has sacrificed the sublingual gland (SLG) with patients which has preserved SLG in intraoral approach. All the patients in this study didn't' have symptoms related to oral dryness after the surgery.

In conclusion, intraoral approach has tolerable postoperative symptoms with no neck scar. 
Although many patients temporarily complained of neurological problems of the lingual nerve and limitation of tongue, they were completely resolved shortly after surgery. However, by the result of long-term follow-up, 2 patients showed tumor recurrence and 2 cases with mild deviation of tongue due to scar contracture after surgery. The main advantages of this approach are no external scar and no permanent injury to the related nerves. Unfortunately, 2 cases showed a recurrence after surgery and required longer term follow-up.

However, we think these problems may be reduced if surgeon's experience of this approach increases.

\section{REFERENCES}

1) Spiro RH. Salivary neoplasms: overview of a 35 -year experience with 2807 patients. Head Neck Surg 1986;8(3):177-84.

2) Krolls SO, Boyers RC. Mixed tumors of salivary glands. Long-term follow-up. Cancer 1972;30(1):276-81.

3) Spiro JD, Spiro RH. Submandibular gland tumors. In: Shockly WM, Pillsbury HC, editors. The Neck: Diagnosis and Surgery. St Louis: Mosby Inc;1994. p.295-306.

4) Hong KH, Kim YK. Intraoral removal of the submandibular gland: a new surgical approach. Otolaryngol Head Neck Surg 2000;122(6): 798-802.

5) Hong KH, Yang YS. Surgical results of intraoral removal of submandibular gland. Otolaryngol Head Neck Surg 2008;139(4): $530-4$.

6) Kauffman RM, Netterville JL, Burkey BB. Transoral excision of the submandibular gland: techniques and results of nine cases. Laryngoscope 2009;119(3):502-7.

7) Milton CM, Thomas BM, Bikerton RC. Morbidity study of submandibular gland excision. Ann R Coll Surg Engl 1986;68(3): 148-50.

8) Turco C, Nision A, Brunetti F. Considerazioni sulle scialoadenectomie sottomandibolare e risultiati a distanza. Minerva Stomatol 1988;37: 329-33.

9) Hong KH, Yang YS. Intraoral approach for the treatment of submandibular salivary mixed tumors. Oral Oncol 2008;44(5):491-5.

10) Guyot L, Duroure F, Richard O, Lebeau J, Passagia JG, Raphael B. Submandibular gland endoscopic resection: a cadaveric study. Int J Oral Maxillofac Surg 2005;34(4):407-10.

11) Terris DJ, Haus BM, Gourin CG, Lilagan PE. Endo-robotic resection of the submandibular gland in a cadaver model. Head Neck 2005; 27(11):946-51.

12) Chen MK, Su CC, Tsai YL, Chang CC. Minimally invasive endoscopic resection of the submandibular gland: a new approach. Head Neck 2006;28(11):1014-7.

13) Erbek SS, Köycü A, Topal Ö, Erbek HS, Özlüoğlu LN. Submandibular gland surgery: our clinical experience. Turk Arch Otorhinolaryngol 2016;54(1):16-20.

14) Springborg LK, Møller MN. Submandibular gland excision: longterm clinical outcome in 139 patients operated in a single institution. Eur Arch Otorhinolaryngol 2013;270(4):1441-6.

15) Bailey BM, Pearce DE. Gustatory sweating following submandibular salivary gland removal. Br Dent J 1985;158(1):17-8.

16) Earley MJ, Stack MM. Gustatory sweating following submandibular gland excision. Br J Plast Surg 1988;41(4):420-1.

17) Haddock A, Porter SR, Scully C, Smith I. Submandibular gustatory sweating. Oral Surg Oral Med Oral Pathol 1994;77(4):317. 